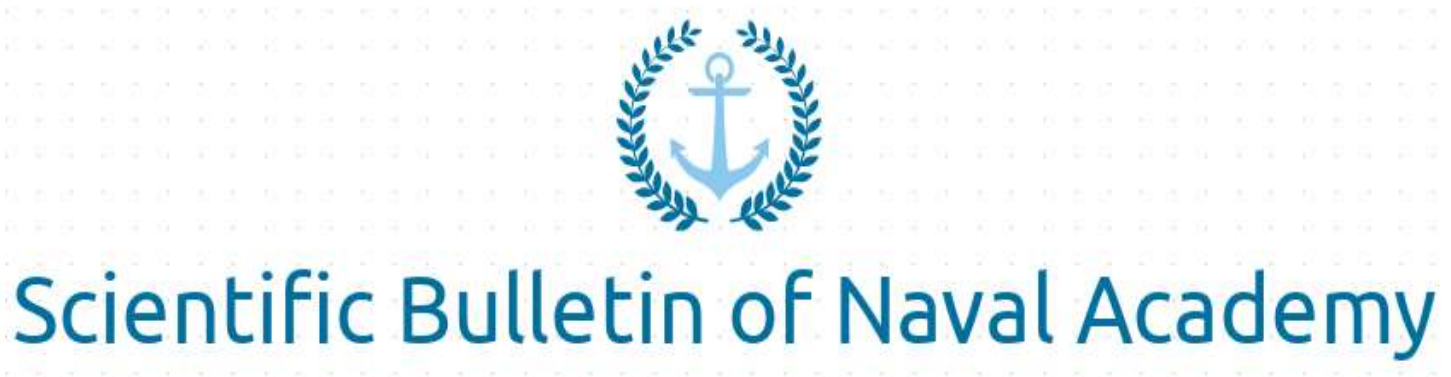

SBNA PAPER • OPEN ACCESS

Switching from traditional to on-line learning-a HOT POTATOES challenge

To cite this article: Apostol-Mates Raluca, Scientific Bulletin of Naval Academy, Vol. XXIII 2020, pg.260-265.

Available online at www.anmb.ro

ISSN: 2392-8956; ISSN-L: 1454-864X

doi: $10.21279 / 1454-864 X-20-12-103$

SBNA@ 2020. This work is licensed under the CC BY-NC-SA 4.0 License 


\title{
Switching from traditional to on-line learning-a HOT POTATOES challenge
}

\author{
APOSTOL-MATES Raluca, Lecturer, Academia Navala 'Mircea cel Batran', \\ Constanta \\ BARBU Alina, Lecturer, Universitatea Maritima Constanta \\ ucamates@yahoo.com \\ alucu013@yahoo.com
}

\begin{abstract}
The present paper is intended to put the light on a very useful and at hand resource for teachers facing the new ways of teaching/ learning approach. Teachers are not IT specialists, but today's learning environment must make them at least familiar with some easy to use, free of charge software. We turned our attention to a friendly one- HOT POTATOES and we gave practical examples of how to use it and what are the results.
\end{abstract}

Motto: "Computers will never replace teachers; but teachers who use computers will replace teachers who do not." (Unknown)

\section{Introduction}

2020. New challenges in our everyday life. It became compulsory to use of facial masks and gloves every time we leave our houses, use of sanitizers after going into a shop, when entering a bank, when going to work. Exceptional measures involving our health were taken due to the SARS-COVID-19 pandemic. No access to school in the traditional form we were used to. Keeping the social distance makes traditional schooling impossible. We all, abruptly switched from keeping our children/ pupils/ students away from PCs and laptops to imposing them as the only means we could use to educate and instruct. And still, numerous children and youngsters, as well as teachers, do not fully know how to use internet resources into education.

We propose a very useful and free of charge software that can help teachers transform traditional printed pages of books to attractive and well based exercises to put on-line.

\section{About Hot Potatoes}

The software was created by Victoria University of Canada: "Half Baked Software". It can be downloaded free of charge, provided that you do not use the software for commercial purposes. By following the step by step online tutorial, you will quickly understand how to use the program. With the help of Hot Pot, any user can create and publish on the Internet several types of exercises in a form of html pages. The first step you need to take to be able to use Hot Pot: register. From the original site http://hotpot.uvic.ca, select the register / registrer option. After completing the form, you will receive a code with your username. You can then launch one of the six Hot Pot subprograms: from the menu select help, then register. You will need to enter the username you registered with and the code, after 
which you will receive a registration confirmation message. You need the password you received when you started building the exercises.

What can we do with Hot Pot? It is an easy-to-use software for both teachers and students and offers several kinds of exercises. As you can see in the image below, reproduced from the original site, on each potato appears the name of a type of exercise: JCloze, JMatch, JMix, JCross, JQuiz. Launch each type of exercise from the main screen after installation.

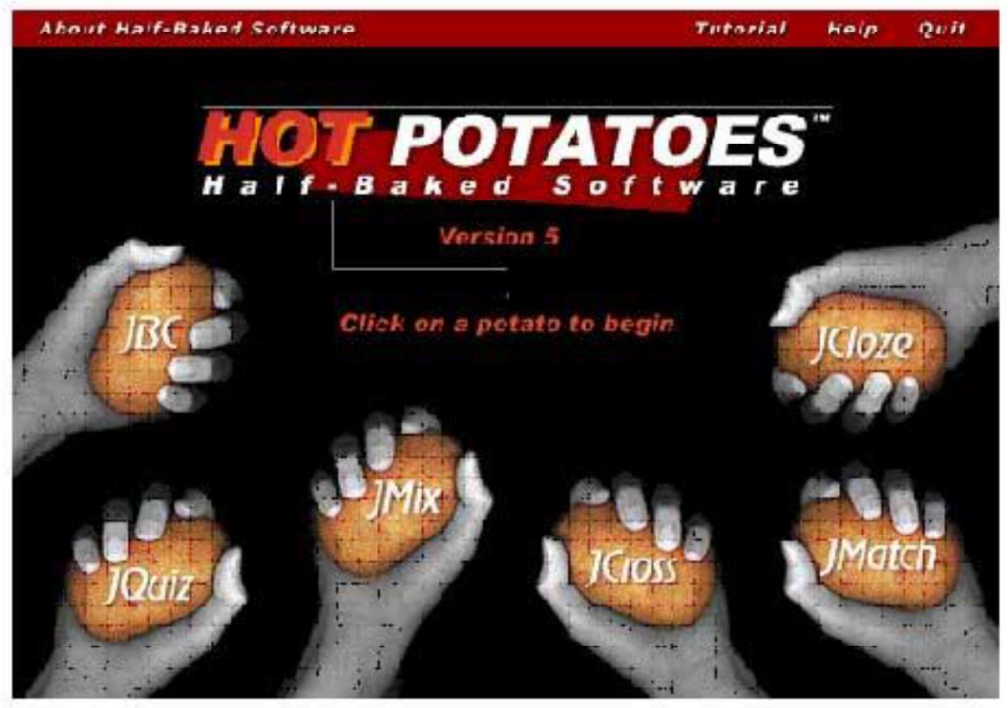

JCloze: exercises such as fill in the blank or exercises à trous, lacunar texts - exercises to fill in the blanks.

JQuiz: multiple-choice questionnaires, questions-answers type. In this type of exercise, you will need to think about as many correct answers as possible; if you do not create them, you may be surprised that the program does not recognize them and tell the student that a correct but unforeseen answer is wrong.

JCross: crossword exercises, ideal for beginners and easy to do. Enter the words you want to use and the program will create the grid.

JMatch generates matching exercises: matching words, sentences, or pictures. Useful especially in vocabulary exercises, it can be done at any level of language knowledge. JMatch asks the student to draw the words next to the corresponding pictures. Five items can be presented, and students must then move the matching terms to the correct positions.

These are easy exercises to do in an on-line format activity, especially with the vocabulary items needed by students for specialized vocabulary. It presents a number of words that you will have to put in the correct order. The exercises only look at short segments, not paragraphs or larger units. The user drags the words and places them in order.

Before creating the desired web page, save your exercises in Hot Pot format. If you accidentally close the program, you will have to repeat all the actions to modify your exercise or launch it in html, which requires basic programming knowledge.

To show how a teacher can transform an already made exercise on paper format into an equivalent exercise on a html page using the above mentioned software, there are some examples included. 
1. A reading exercise followed by an mind-mapping exercise in printed format could be transformed into a fill-in-the-gaps exercise and accessed into a html page-form:

\section{Read the following text:}

A fire, if detected quickly, can be fought and brought under control with a minimum of damage. The use of fire detection devices is, therefore, increasing particularly in view of reduced manning and unmanned machinery spaces.

Three phenomena associated with fire are used to provide the alarm: smoke, flames, and heat.

The smoke detector makes use of two ionisation chambers, one open to the atmosphere and one closed. The fine particles or aerosols given off by the fire alter the resistance in open ionisation chamber, resulting in operation of a cold cathode gas-filled tube. The alarm sounds on the operation of the tube to give warning of fire. Smoke detectors are used in machinery spaces, accomodation areas and cargo holds.

Flames, as opposed to smoke, are often the main result of gas and liquid fires and flame detectors are used to protect against such hazard. Flames give off ultraviolet and infra-red radiation and detectors are capable to respond to either. Flame detectors are used near to fuel handling equipment in the machinery spaces and in such spaces as boiler rooms.

Heat detectors can use any of a number of principles of operation, such as liquid expansion, low melting point materials or bimetallic strips. The most usual detector nowdays operates on either a set temperature rise or a rate of temperature rise being exceeded. Thus an increase in temperature occuring quickly could set off the alarm before the set temperature was reached. Heat detectors are used in places such as the galley and laundry where other types of detectors would give off false alarms.

\section{Complete the following scheme with information from the text:}

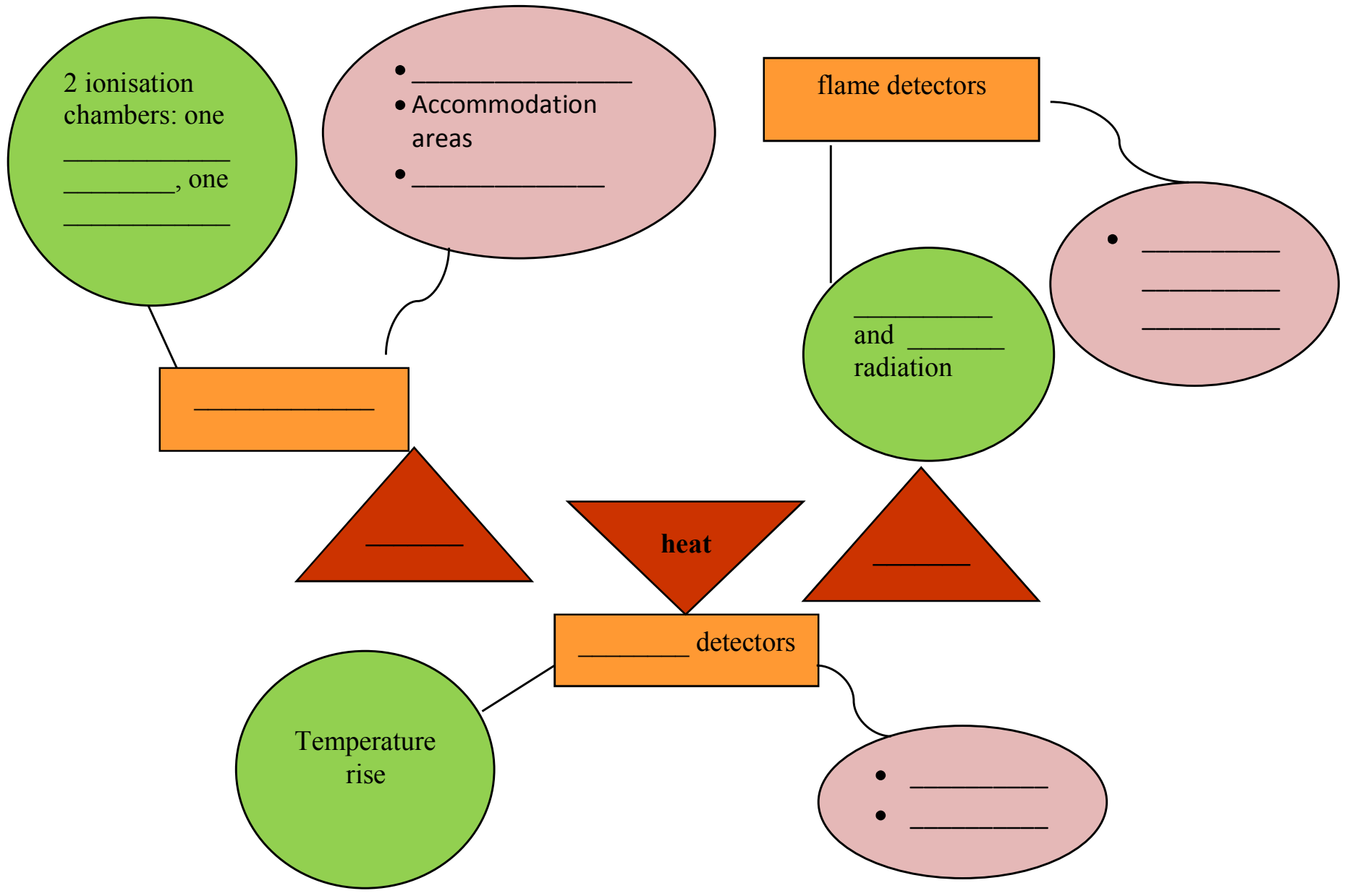




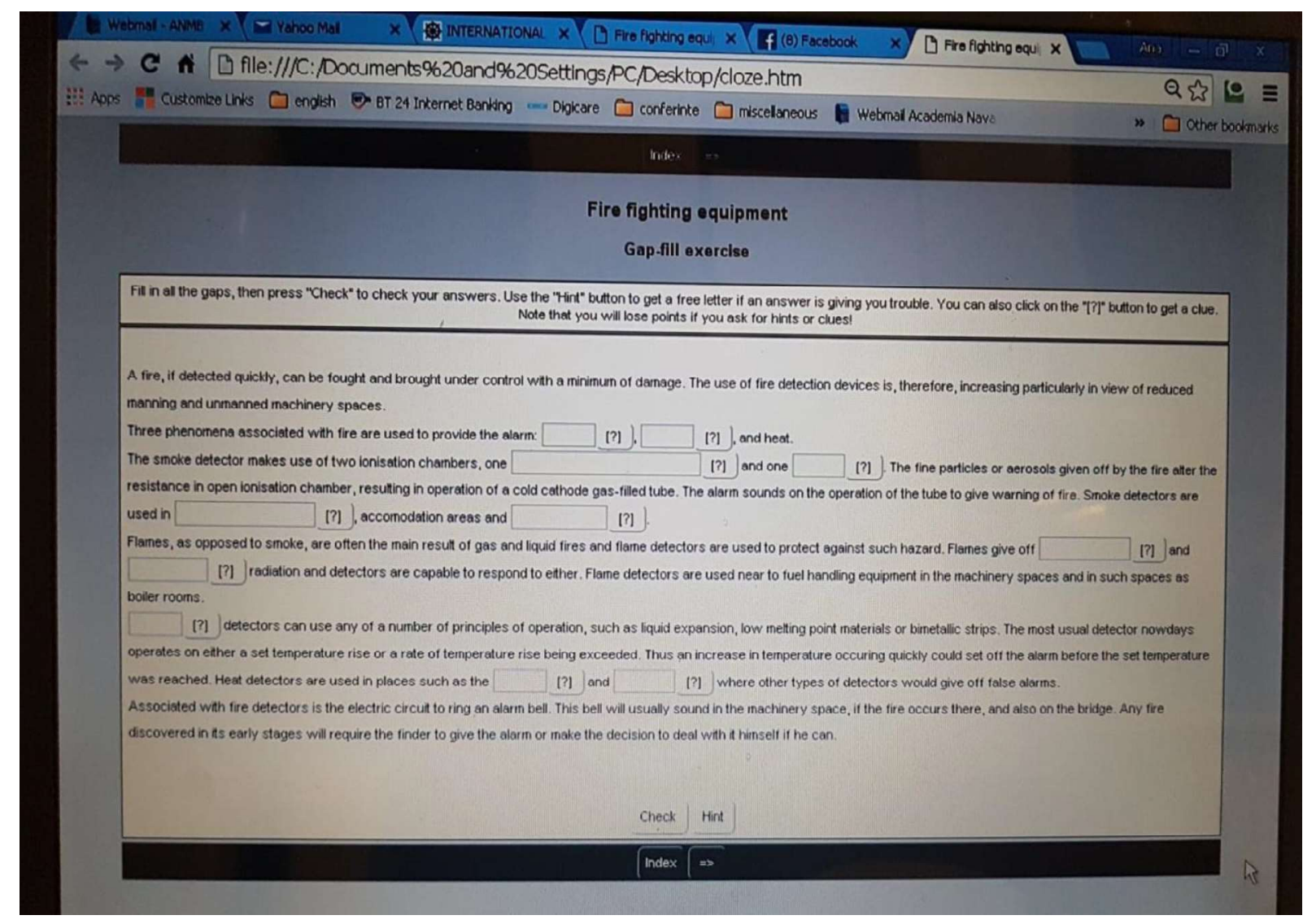

2. The previously given exercise could also be transformed into a quiz exercise. We chose the shortanswer format of the answers from the 4 given types: multiple-choice, short-answer, hybrid, multiselect.

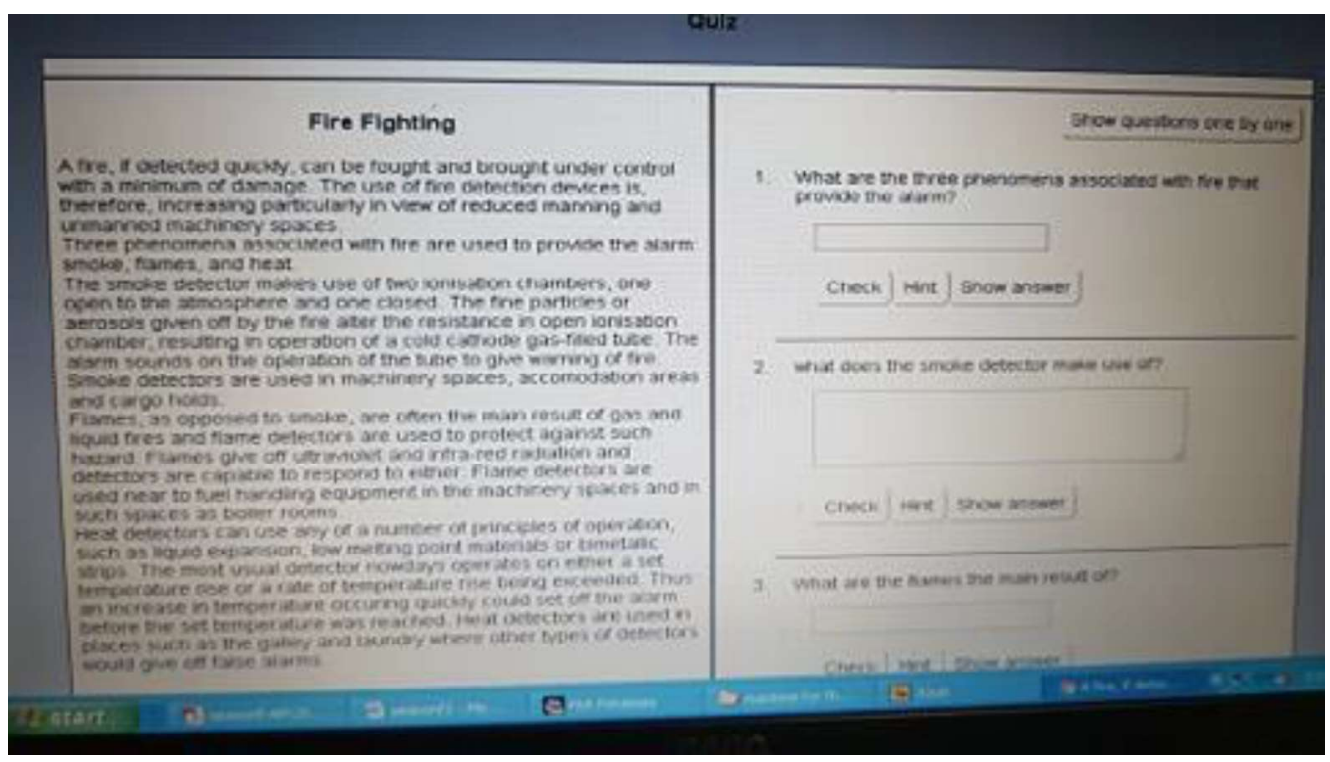




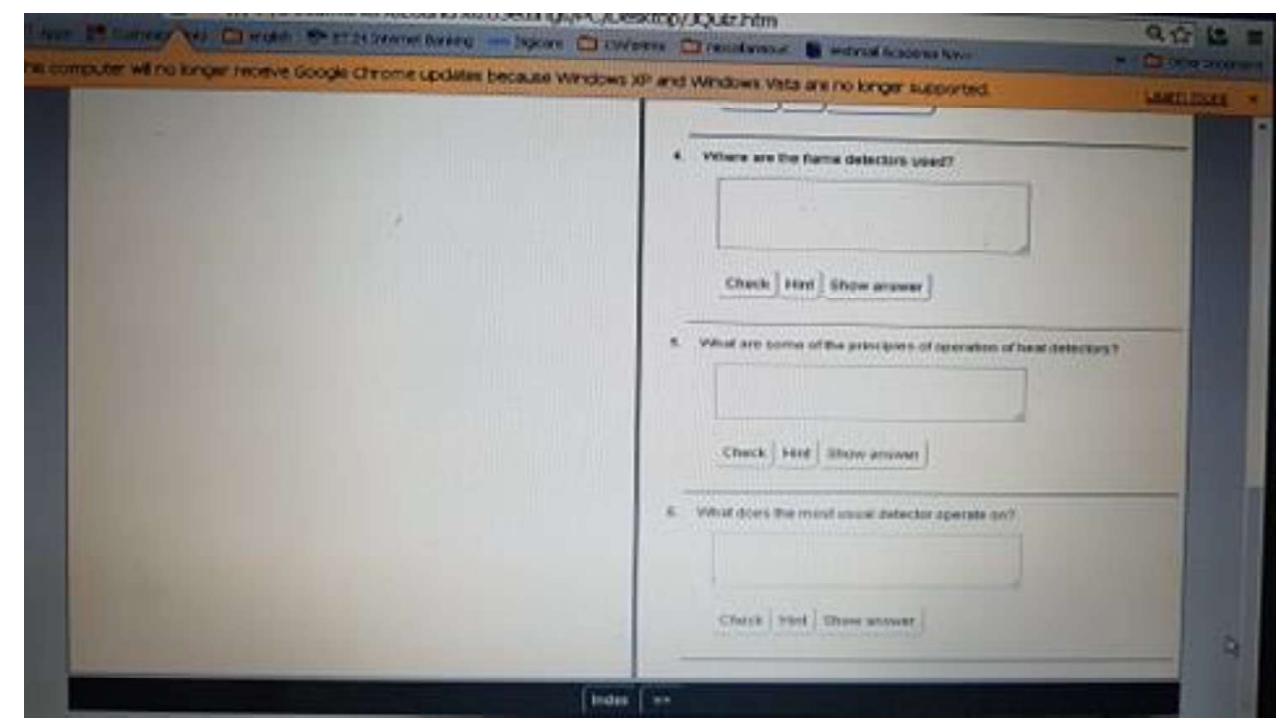

3. A common matching exercise, that had been previously solved using the lines drawn with the pencil, was transformed into an on-line exercise based on the drag-and-drop technique.

\section{Match the words with their definitions:}

damage

smoke

detectors

radiation

expansion

melting point

bimetallic

detector the temperature at which something melts

composed of two different metals —often used of devices having a part in which two metals that expand differently are bonded together a device that can tell if a substance or object is present physical harm that is done to something or to someone's body energy that comes from a source in the form of waves or rays you cannot see the act of becoming bigger or of making something bigger an alarm that activates automatically when it detects smoke

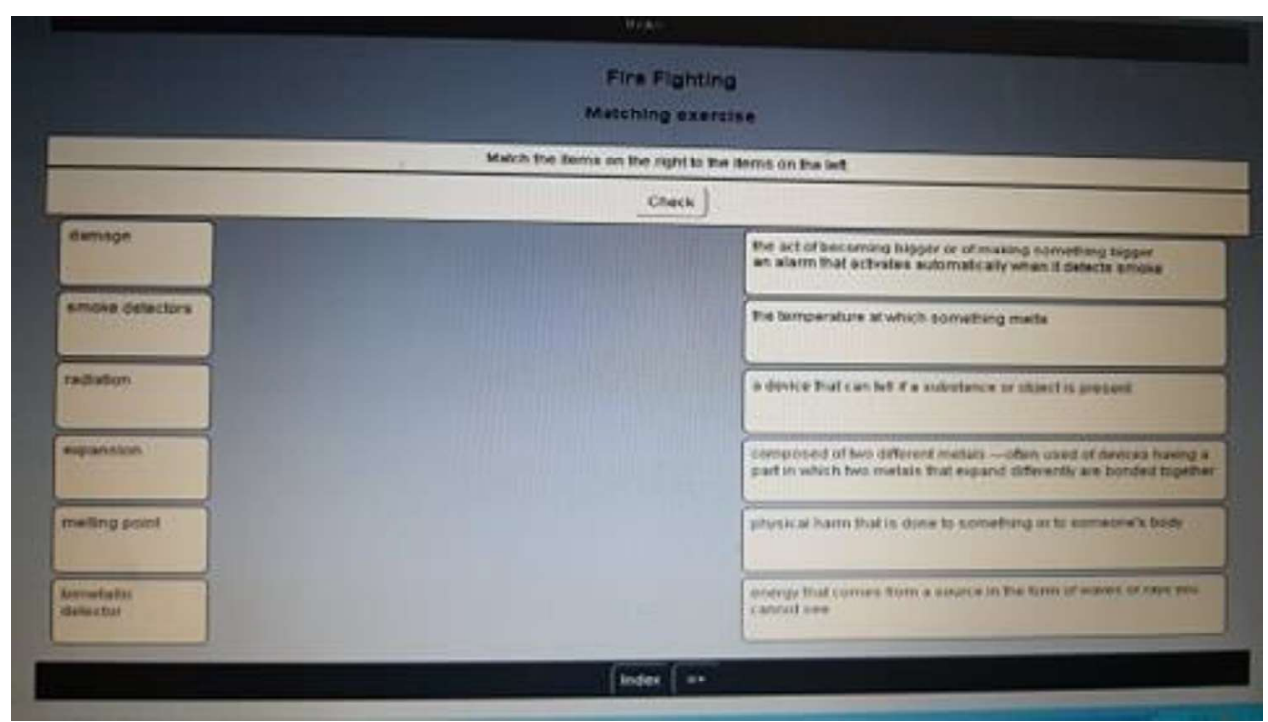


4. A mixed-sentence exercise does not change much. The form remains the same, the access changes from numbering the words into the correct order to form the sentence to drag-and-drop words into the logical sentence.

Put the following words into the corect order to form a sentence:

Room, kept, clean, the, should, and, engine, tidy, be. (The engine room should be kept clean and tidy.)

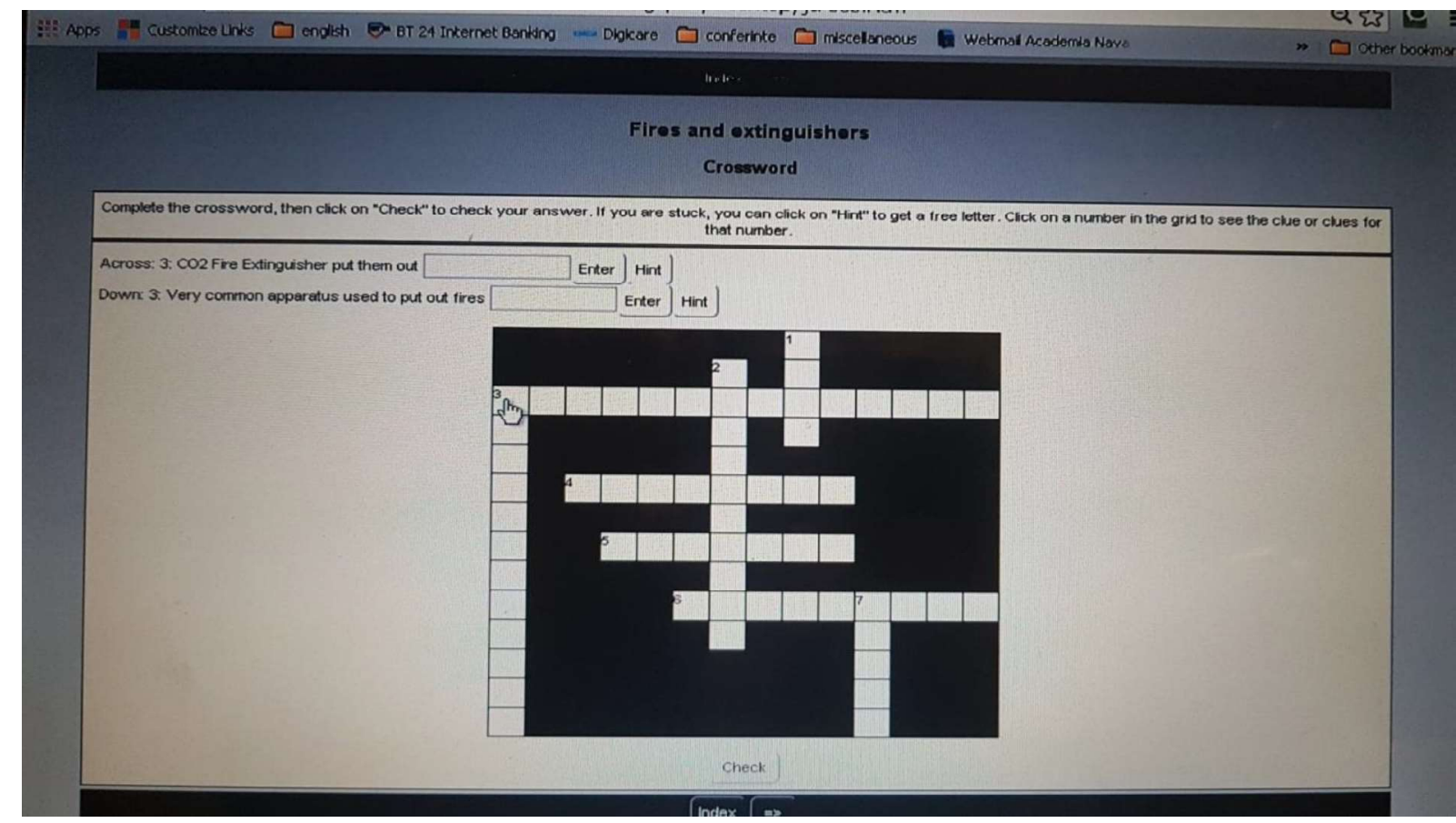

\section{Conclusion}

In addition to using the computer in the classroom, teachers should encourage students to use sites for learning foreign languages through games, chats with natives, competitions. There are many sites that offer interesting exercises for all levels of language skills. But can the computer still replace the teacher? Given the need for motivation and socialization in learning, providing individual tutoring and guidance, we believe not entirely. But the computer can make the language lesson more fun and interesting, and from learning a language, a personal development exercise.

\section{References}

[1] http://hotpot.uvic.ca

[2] A study of teachers' use of online learning resources to design classroom activities,

M. Recker,A. Walker,S. Giersch,X. Mao,S. Halioris,B. Palmer,D. Johnson,H. Leary \&M. B. Robertshaw,

https://www.tandfonline.com/doi/abs/10.1080/13614560701709846? src=recsys\&journalCode=tham20

[3] Comparing the Effectiveness of Classroom and Online Learning: Teaching Research Methods, Anna Ya Ni, https://www.tandfonline.com/doi/abs/10.1080/15236803.2013.12001730? src=recsys [4] Designing a materials development course for EFL student teachers: principles and pitfalls Marina https://www.tandfonline.com/doi/abs/10.1080/17501229.2015.1090994?journalCode=rill20

Bouckaert, 